
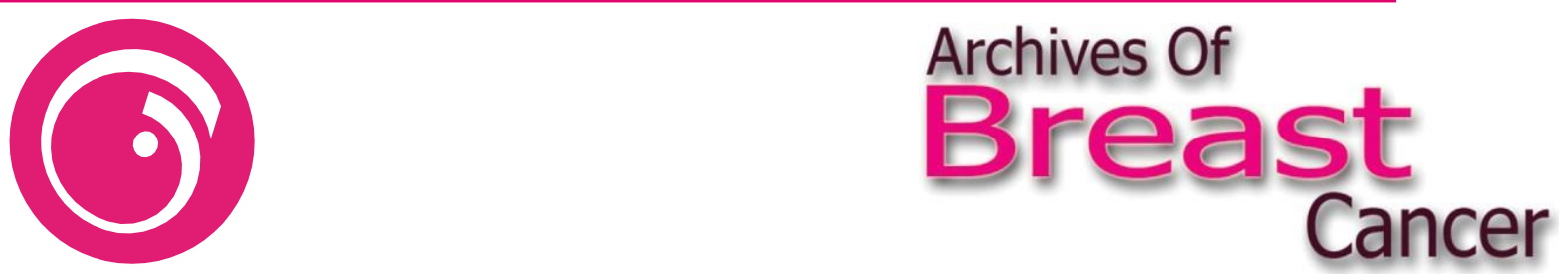

DOI: $10.32768 / a b c .2022911-3$

\title{
Opiophobia in Palliative Care: Conquering the Last Hill
}

\author{
Mamak Tahmasebi*a \\ ${ }^{a}$ Department of Palliative Medicine, Tehran University of Medical Sciences, Tehran, Iran
}

Copyright (C) 2022. This is an open-access article distributed under the terms of the Creative Commons Attribution-Non-Commercial 4.0 International License, which permits copy and redistribution of the material in any medium or format or adapt, remix, transform, and build upon the material for any purpose, except for commercial purposes.

Opioids are among the most challenging medications. As physicians, we prescribe opioids at least once throughout our careers, including codeine, tramadol, pethidine, methadone, or morphine. At the same time, we continue to have concerns about side effects and fallacies associated with opioids despite years of knowledge and experience. Studies demonstrate that cancer patients are often under-prescribed with opioids resulting in preventable and unnecessary suffering. ${ }^{1}$ Here is a case report of how the prescription of morphine can cause a complicated situation:

Ms. G. was 68 years old suffering from dyspnea for the past three weeks. She was admitted to the emergency department where her severe right pleural effusion was managed by inserting a tube thoracostomy. She was a known case of triple-negative breast cancer for two years, and despite all therapeutic interventions, cancer had spread to the bones and lungs. Thoracentesis only slightly relieved her dyspnea. The oncologist referred her to the palliative care clinic for symptom management, specifically pain and dyspnea. She lived with her only daughter (Ms. K.) and preferred staying at home as much as possible. On the day of the visit to the palliative clinic, Ms. K. arrived while pushing her mother in a wheelchair. Ms. K. complained that her mother had been barely eating or drinking anything over the past month. She was in pain, and dyspnea hindered her ability to speak. A palliative care physician prescribed morphine to alleviate her pain and dyspnea. It included $2.5 \mathrm{mg}$ subcutaneous injection of morphine q6h and additional injection as needed. The

\footnotetext{
${ }^{\star}$ Address for correspondence:

Mamak Tahmasebi

Department of Palliative Medicine, Tehran University of

Medical Sciences, Tehran, Iran

Tel: +98216658 1542

Email: mamaktahma@yahoo.com
}

following week, Ms. K. returned to the clinic in a black outfit. Bursting into tears, she shouted at the physician that her mother died the day after receiving morphine and that a paramedic staff who had transported Ms. G.'s body had told her the morphine caused respiratory suppression and death.

\section{History of Opium}

According to most experts, the Sumerians were the first who cultivated opium in 3400 B.C. in lands currently located in Iraq. They acknowledged its euphoric properties by calling it Hul Gil, or "joy plant." Medical texts left by the Egyptians from 1500 B.C. indicate that opium could be found in more than 700 medicines. Hippocrates (460-357 B.C.), the "Father of Medicine," recognized opium's healing effects, and Avicenna recommended it, especially in cases of diarrhea and eye diseases. ${ }^{2}$

For the first time, Friedrich Sertürner, a German scientist, isolated morphine, the active ingredient in opium, in 1803, and a German pharmaceutical company, E. Merck \& Company, began manufacturing morphine commercially in $1827 .{ }^{3}$

Growing numbers of studies and scientific evidence highlight the significance of opioids as a treatment option for cancer patients who suffer from pain and dyspnea. Despite the World Health Organization (WHO) guidelines for the use of opioids in managing pain in cancer patients, ${ }^{4}$ "opiophobia," which refers to a doctor's unwillingness to prescribe opioids, remained a major medical obstacle in many countries including Iran. Oncologists prefer recommending opium over opioid medications, based on unreported observations. Physicians' reluctance to prescribe opioids is primarily due to the lack of a formal program in their medical curriculum and illogical concerns about opioid side effects. $^{5}$

Due to misconceptions regarding opioids, palliative care clinics face challenges encouraging patients to use 
morphine to alleviate severe pain or dyspnea. Most physicians, even pain specialists, ${ }^{6}$ and nurses have unfounded concerns about prescribing opioids. Morphine, when appropriately administered, has fewer side effects than over-the-counter pain relievers, such as NSAIDs. As well as commonly known side effects such as constipation, nausea, and sedation, morphine is also notorious for addiction, respiratory depression, and hastening death, as I will briefly describe in the following paragraphs.

\section{Addiction}

Fear of addiction is one of the significant reasons that dissuade physicians from prescribing opioids to relieve pain associated with cancer. Opioid addiction is, however, a rare condition. With no previous history of addiction, fewer than two out of every 10,000 people will become addicted to opioids. ${ }^{7}$ It is important to emphasize that physical dependence and tolerance are normal physiologic responses to opioids and should not be confused with addiction.

Respiratory depression

Respiratory depression remains a primary concern in opioid usage among nurses and physicians. Respiratory depression occurs in less than $0.5 \%$ of patients postoperatively, and it is scarce among those under chronic opioids prescription. ${ }^{8} 9$ Substantial evidence supports the beneficial effects of opioids in treating breathlessness, indicating that opioids are safe for managing dyspnea even in patients with cardiopulmonary diseases..$^{10}$ Pain stimulates the respiratory center; therefore, opioids may cause respiratory depression if clinicians do not adjust opioid dosage appropriately after managing pain in a short time, for example, after nerve block.

\section{Hastening death}

Although there is no evidence that the use of opioids for the management of cancer pain negatively impacts survival, it remains a subject of intense discussion. Concern over opioids' side effects and the common practice of prescribing morphine to dying patients, ${ }^{11}$ explains why opioids are often misconstrued as the cause of death. Studies demonstrate that good pain management is beneficial for sleep and appetite, and as a consequence, improves the quality of life and even survival. ${ }^{12}$

The Basic rules for morphine prescription:

- Morphine is the gold standard in managing severe pain in cancer patients and dyspnea with unresolved causes. ${ }^{13,14}$

- The only dose-limiting factor is intolerable side effects. Patients determine their morphine doses based on the severity of pain and dyspnea they are experiencing. ${ }^{4}$

- For managing chronic pain, morphine should be prescribed regularly and not as needed (p.r.n). ${ }^{4}$
- The administration of morphine subcutaneously is the best route for patients who have difficulty swallowing their drugs or when transdermal route is not feasible. ${ }^{4}$

- Precautions need to be taken when prescribing morphine to patients with renal or hepatic failure. ${ }^{12}$

- A laxative must almost always accompany morphine prescriptions. ${ }^{9}$ In some patients, managing constipation is even more complicated than pain.

\section{CONCLUSION}

Pain is a subjective unpleasant experience, so clinicians have the opportunity to change cancer patients' experience with good and appropriate pain relief. According to Dame Cicely Saunders, pain goes far beyond the physical, including psychological, social, and emotional aspects. ${ }^{15}$ Only after treating severe physical pain with morphine can healthcare providers address other aspects of pain. As a rule, every oncologist must know the principles of morphine therapy: by the clock, by the mouth, by the ladder, and by the individual. All health care providers should know enough about opioids to provide accurate information to patients and their families (such as Ms. K.). The management of cancer pain should be free from myths and superstitions.

Suppose the palliative care physician could have taken the time to discuss Ms. G's care goals based on her prognosis, clarified her preferences, and explained to her and her daughter the common side effects of opioids. In that case, Ms. K might accept her mother's death without remorse and ambiguity. Good comprehensive care involves communication and shared decisions, which are the corner stones of medical care as a technical and ethical process.

\section{CONFLICT OF INTEREST}

None.

\section{REFERENCES}

1. Knaul FM, Farmer PE, Krakauer EL, De Lima L, Bhadelia A, Kwete XJ, et al. Alleviating the access abyss in palliative care and pain relief - an imperative of universal health coverage: the Lancet Commission report. The Lancet. 2018;391(10128):1391-454. doi: 10.1016/S01406736(17)32513-8.

2. Norn S, Kruse PR, Kruse E. History of opium poppy and morphine. Dansk medicinhistorisk arbog. 2005;33:171-84. doi: Not available.

3. Santella TM, Triggle DJ. Opium: Infobase Publishing; 2007. ISBN: 0-7910-8547-3. doi: Not Available

4. Committee WGAbtGR. WHO guidelines for the pharmacological and Radiotherapeutic Management of Cancer Pain in adults and adolescents. Geneva: World Health Organization,(c) World Health Organization. 
2018;2018. ISBN:978 924 1550390. Available at: https://www.who.int/publications-detailredirect/9789241550390

5. Saca ML, Centeno C. Reaffirming the benefits of morphine to beat opiophobia. European journal of palliative care. 2015;22(6):288-91. doi: Not available.

6. Lipman AG. Does Opiophobia Exist Among Pain Specialists? Journal of Pain \& Palliative Care Pharmacotherapy. 2004;18(2):1-5. doi: 10.1080/J354v18n02_01.

7. Abrahm JL. A physician's guide to pain and symptom management in cancer patients: JHU Press; 2015. ISBN: 9781421414034 . doi: Not Available

8. Dahan A, Aarts L, Smith TW. Incidence, reversal, and prevention of opioid-induced respiratory depression. The Journal of the American Society of Anesthesiologists. 2010;112(1):226-38. doi: 10.1097/ALN.0b013e3181c38c 25.

9. Bruera E, Higginson I, Gunten C, Morita T. Textbook of Palliative Medicine and Supportive Care CRC Press; 2021. ISBN 9780367642037. doi: Not Available

10. Thomas JR, von Gunten CF. Clinical management of dyspnoea. The Lancet Oncology.
2002;3(4):223-8. doi: 10.1016/s14702045(02)00713-1.

11. Bemand-Qureshi L, Gishen F, Tookman A. Opioid use in palliative care: new developments and guidelines. Prescriber. 2019;30(4):25-31. doi: 10.1002/psb. 1755.

12. Howard PT, Robert G.; Wilcock, Andrew. PCF6 : palliative care formulary2017. ISBN 978-09928467-4-9. Available at: https://www.palliativedrugs.com/assets/pcf6/Preli ms_PCF6.pdf

13. Wiffen PJ, Wee B, Derry S, Bell RF, Moore RA. Opioids for cancer pain-an overview of Cochrane reviews. Cochrane Database of Systematic Reviews. 2017(7). doi: 10.1002/14651858.CD012592.pub2.

14. Crombeen A, Lilly E. Management of dyspnea in palliative care. Current Oncology. 2020;27(3):1425. doi: $10.3747 /$ co.27.6413.

15. Clark D. 'Total pain', disciplinary power and the body in the work of Cicely Saunders, 1958-1967. Social Science \& Medicine. 1999;49(6):727-36. doi: 10.1016/s0277-9536(99)00098-2.

\section{How to Cite This Article}

Tahmasebi M. Opiophobia in Palliative Care: Conquering the Last Hill. Arch Breast Cancer. 2022; 9(1):1-3.

Available from: https://www.archbreastcancer.com/index.php/abc/article/view/461 